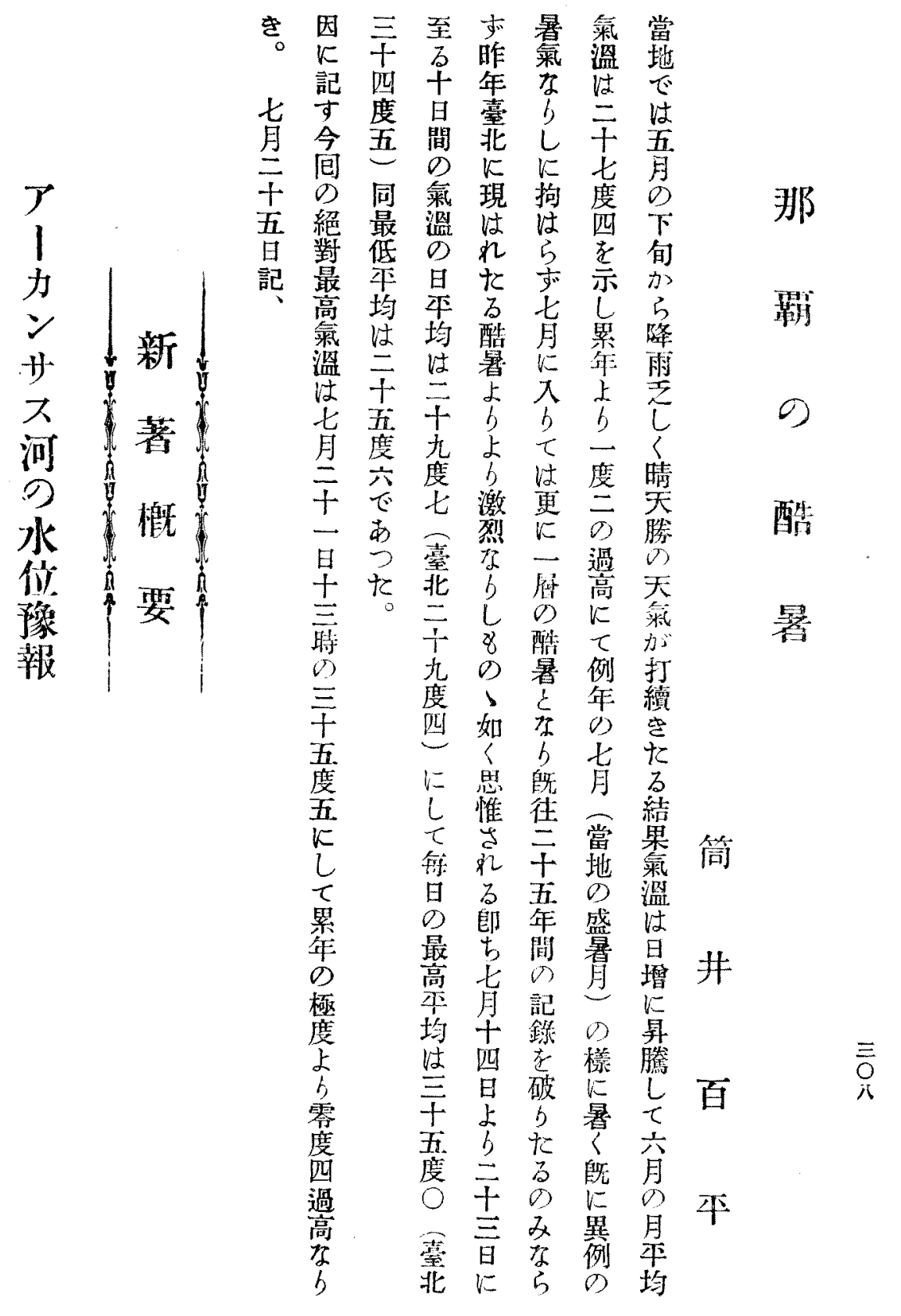




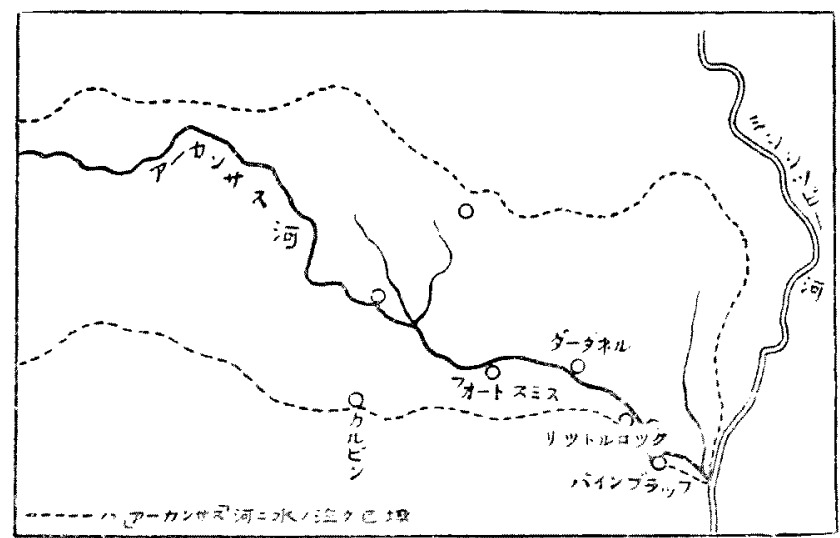

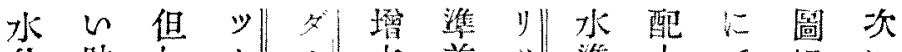

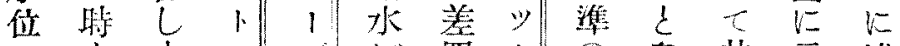

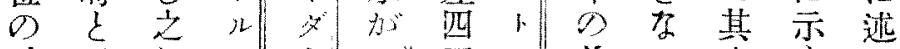

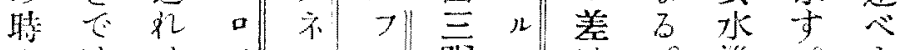

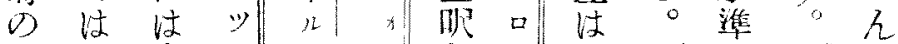

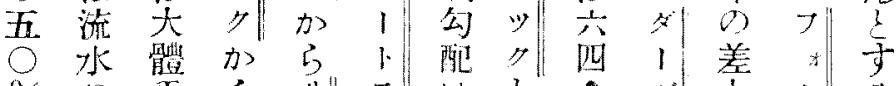

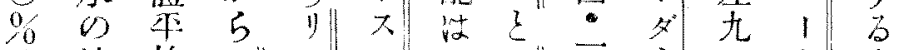

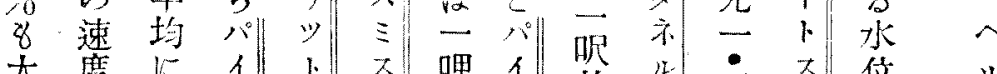

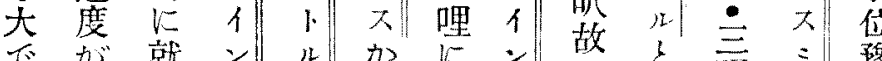
あ゙ が

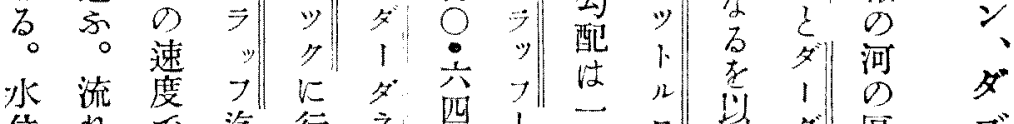

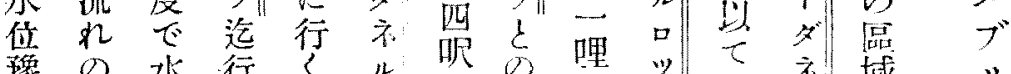
䂈の水行? 几

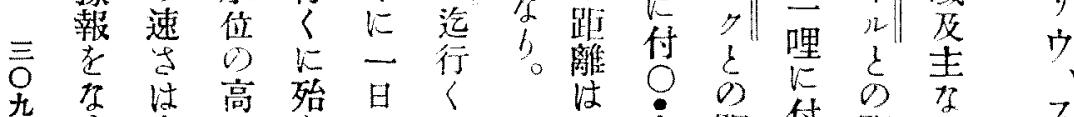

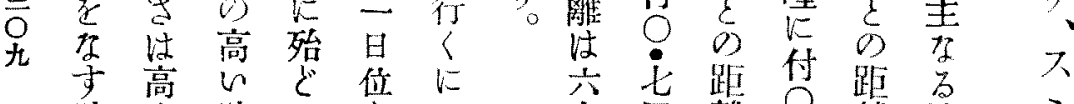

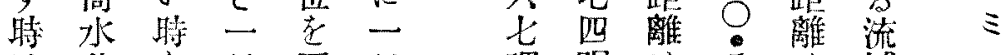
は位之日要旦嘿呎永注域不

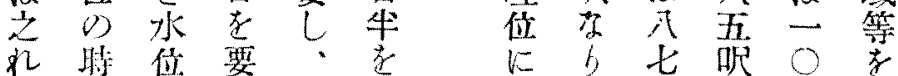

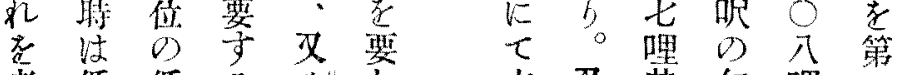

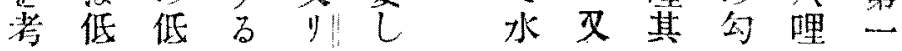



左 パ高架均 量 事 强

D ン 测 雨 河用 0

望 ブ所量川要降

明 $三$ 分深雨

第 フ|⿴囗大

圖注告磪 ら お告

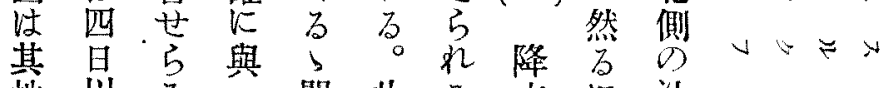

地以るへ間此る水に泩

方前子るに豫主量其水

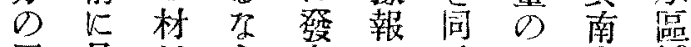

平最料 万表恃㭙吕方域

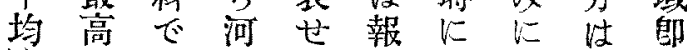

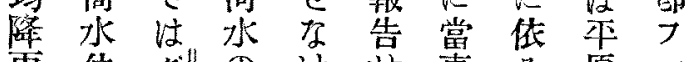

雨位夘のけ豪方原衫

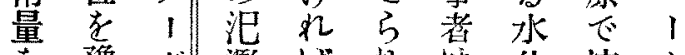

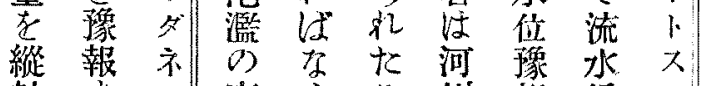

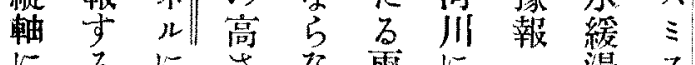

にる に尤尔雨に 漫

取事於老的量於

名出は密若基豫

1 來三背云期

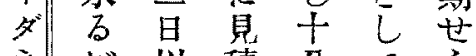

ネが 齐積 分て ら

几 前方菜劣

K 呎 $匚$ 事

於坫り唯吕等最

计至ッ出雨的高

名上來量机水

最主儿总觀成位

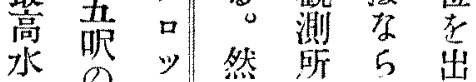

位 の

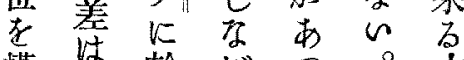

横先狑が少。交

軸免ててらて師速

机沈現其豫汇

取尔点在地報豫

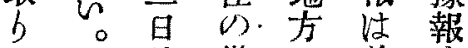

前僅 D基导

㝠 $V$ 分平氷方

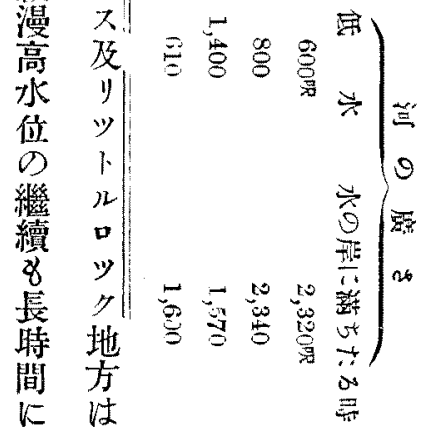

間旅

这

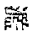

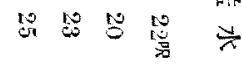

$\vec{F}$

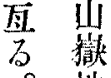

地

水

D

注

ほ

速

b) 


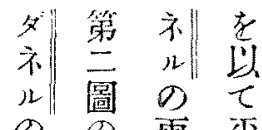

$\infty$ 雪

预曲量均

報 線更丽

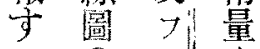

万 01 है

水 端 11 方

位 朝

だに ス の

あ 其 ミ॥だ

3 雨 大虫

量地方。

取的例

5 觀 几

水測住

柋所今

№v

他雪 1

量名

) 亦

最㳀的

到定

D世水

长与位

位的豫

o) 万報

曲。在

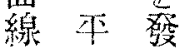

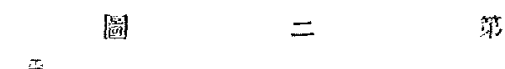

以均世

出

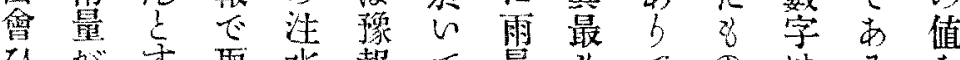

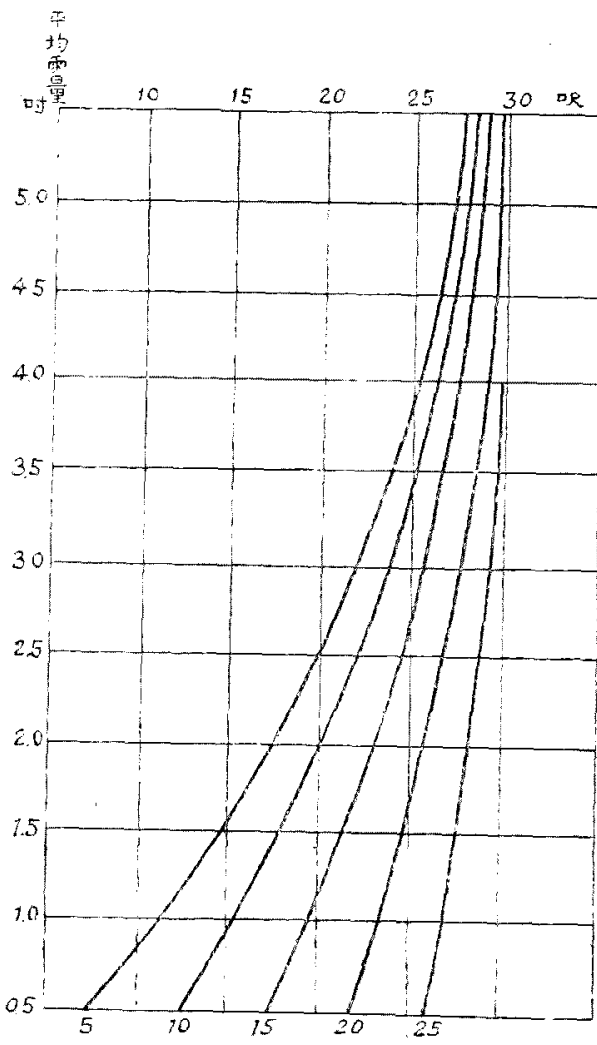

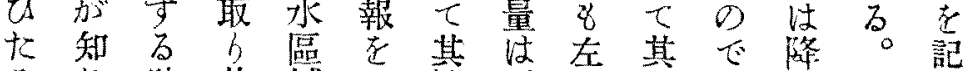

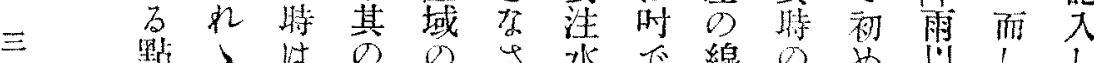

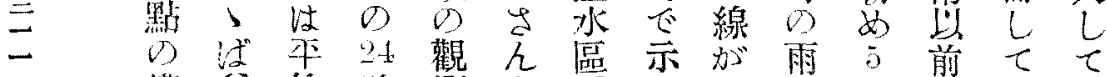

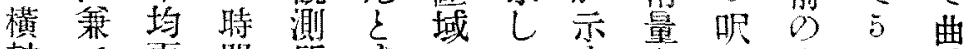

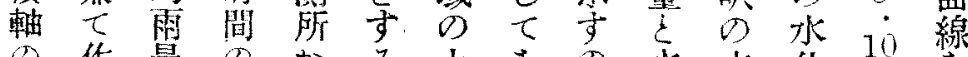

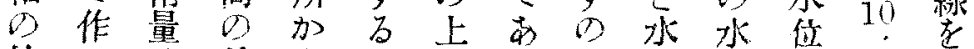
侹了蝶 5 所

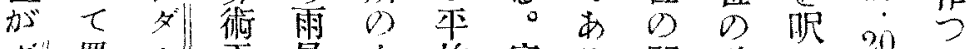

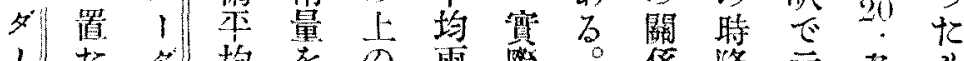

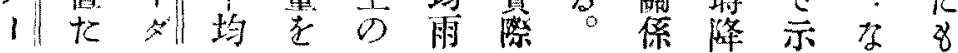




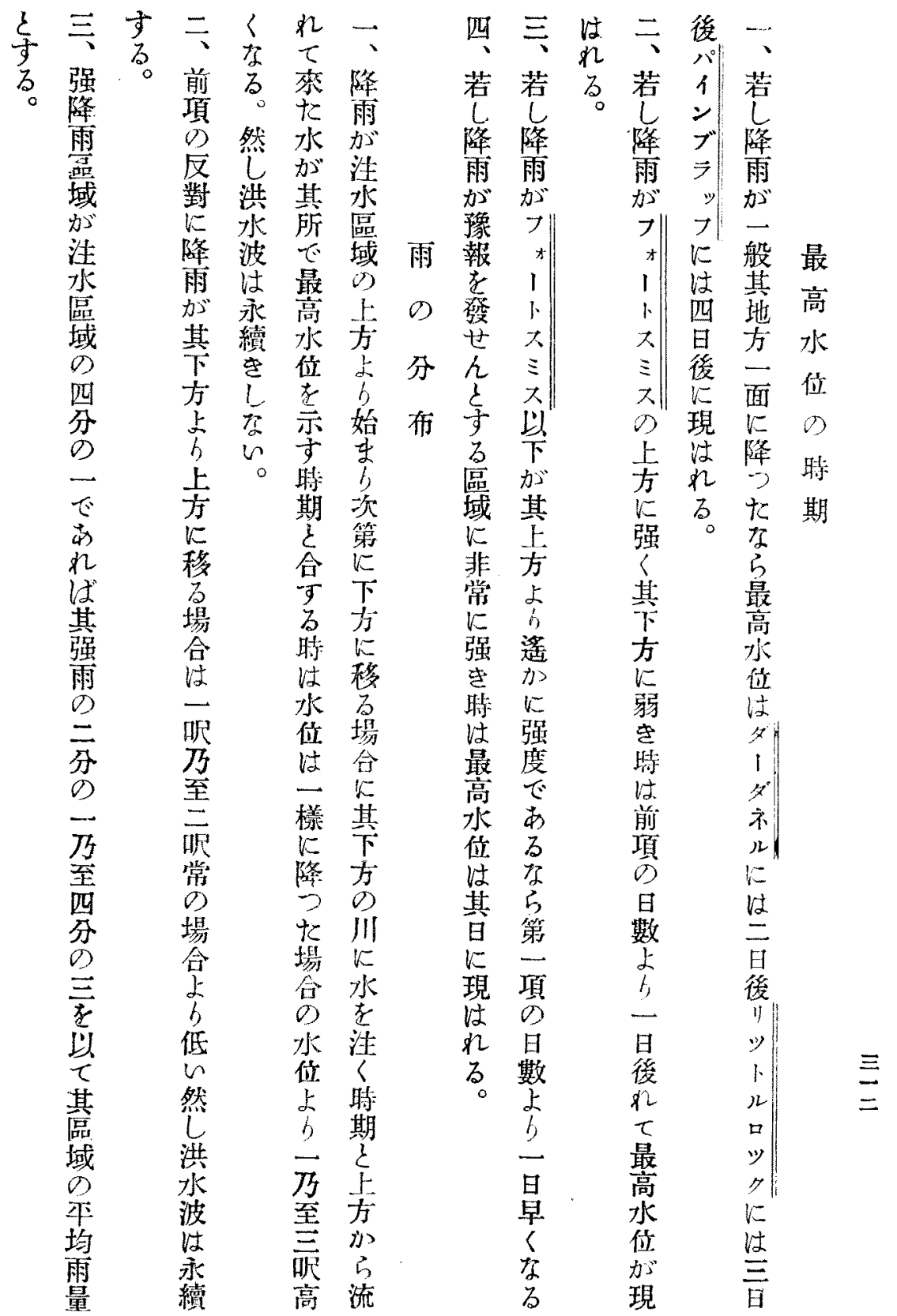




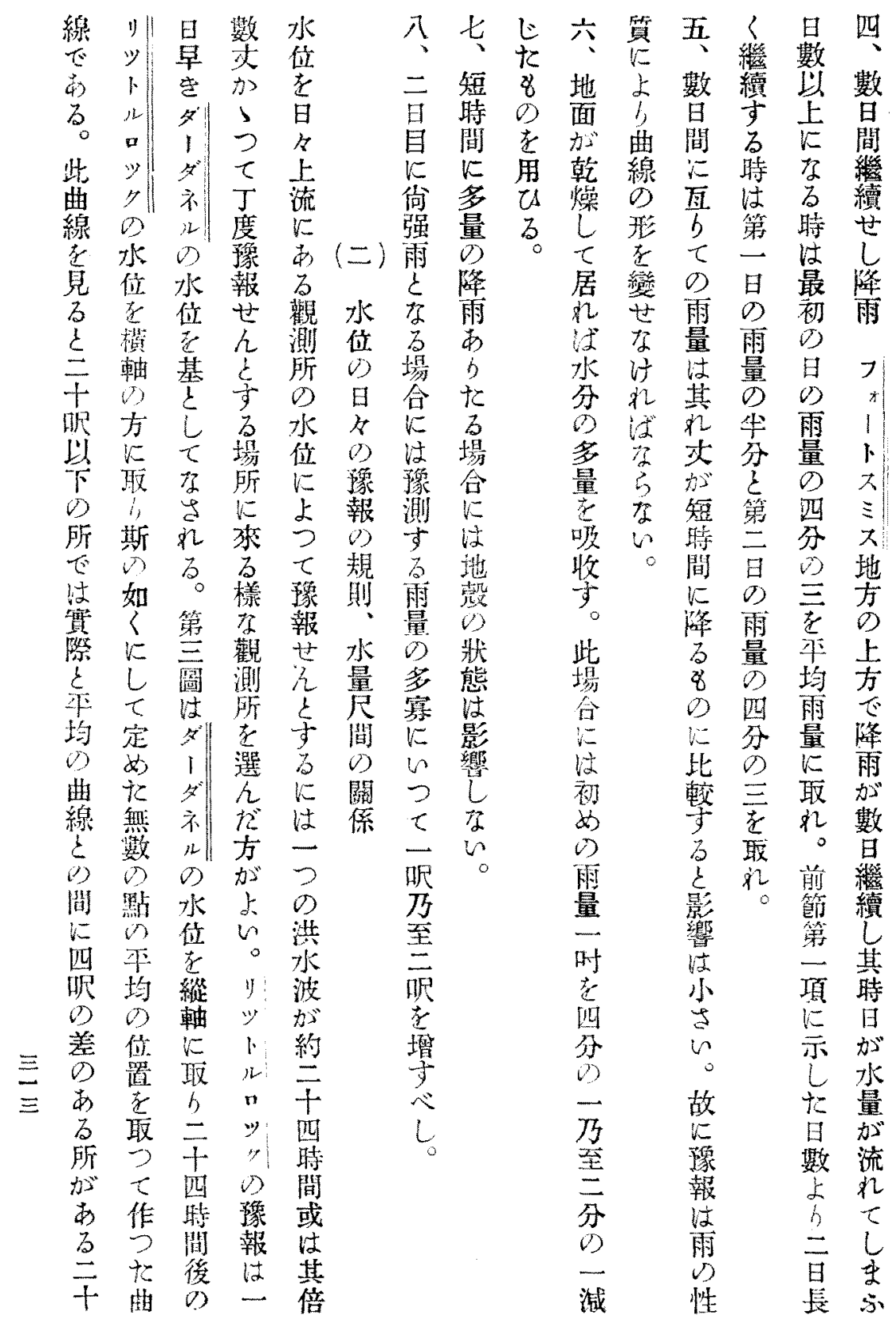



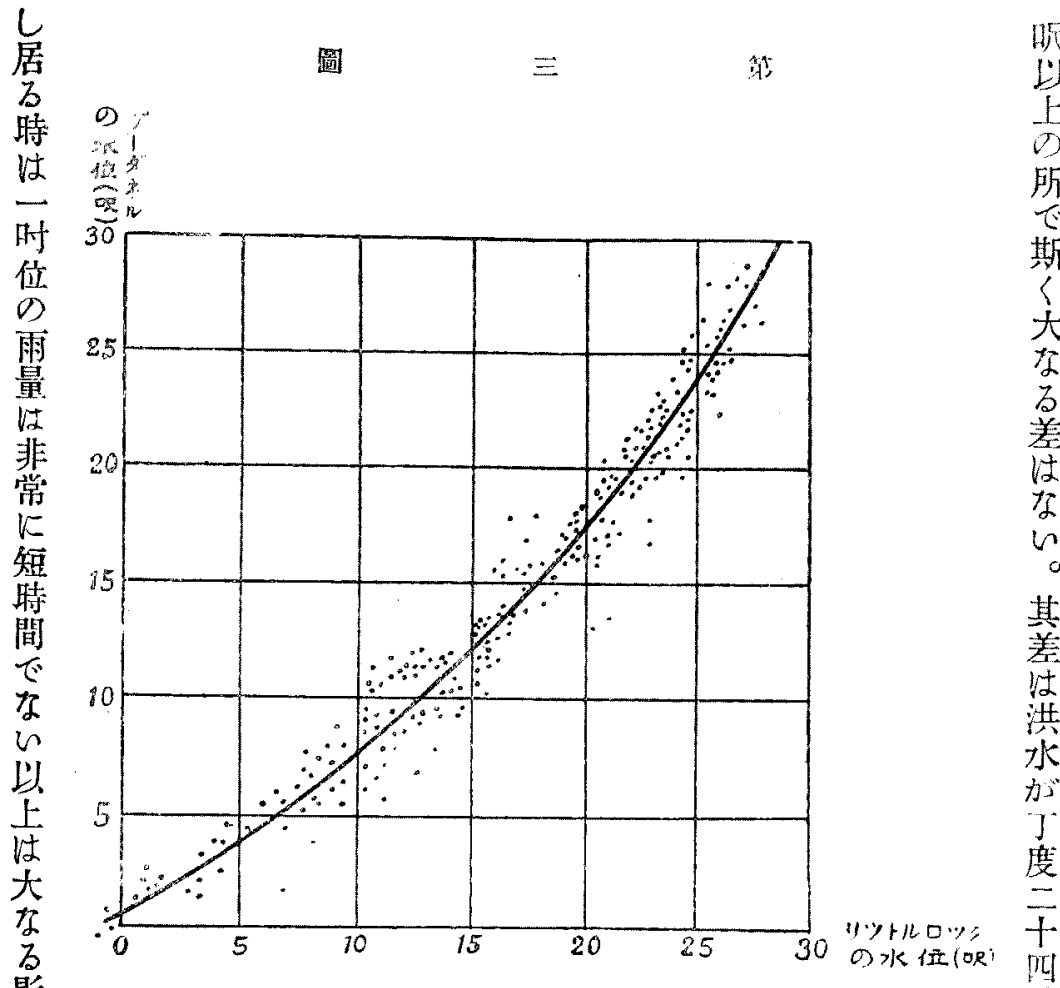

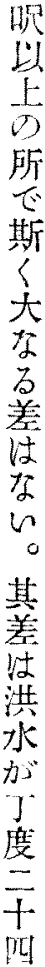

\section{- $>$ 原㭙}

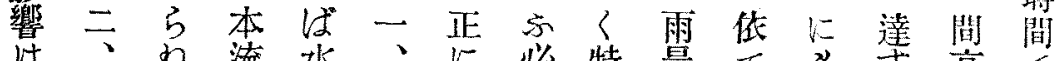

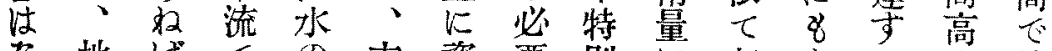

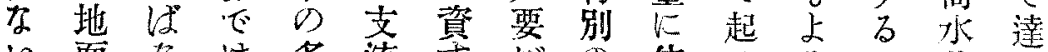

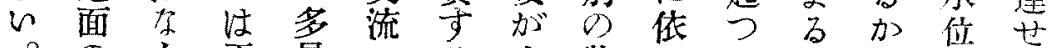
の 5 平量 る

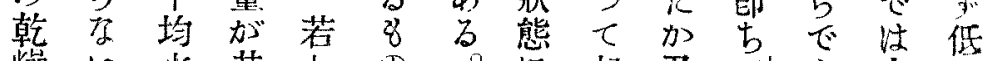

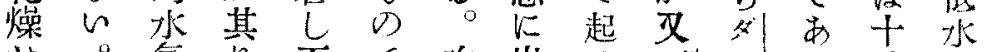

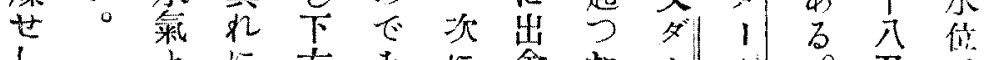

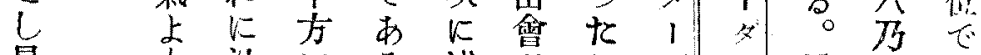
量 b) b 泩

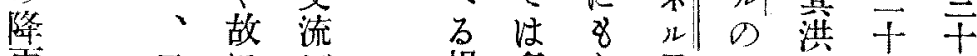

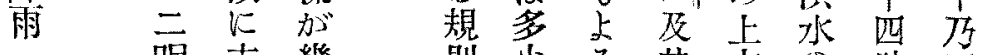

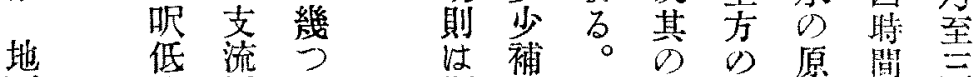

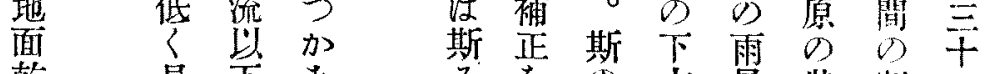
乾見卢

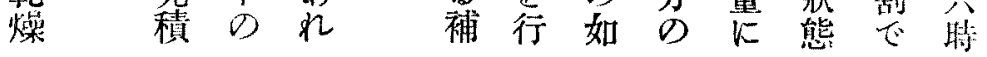




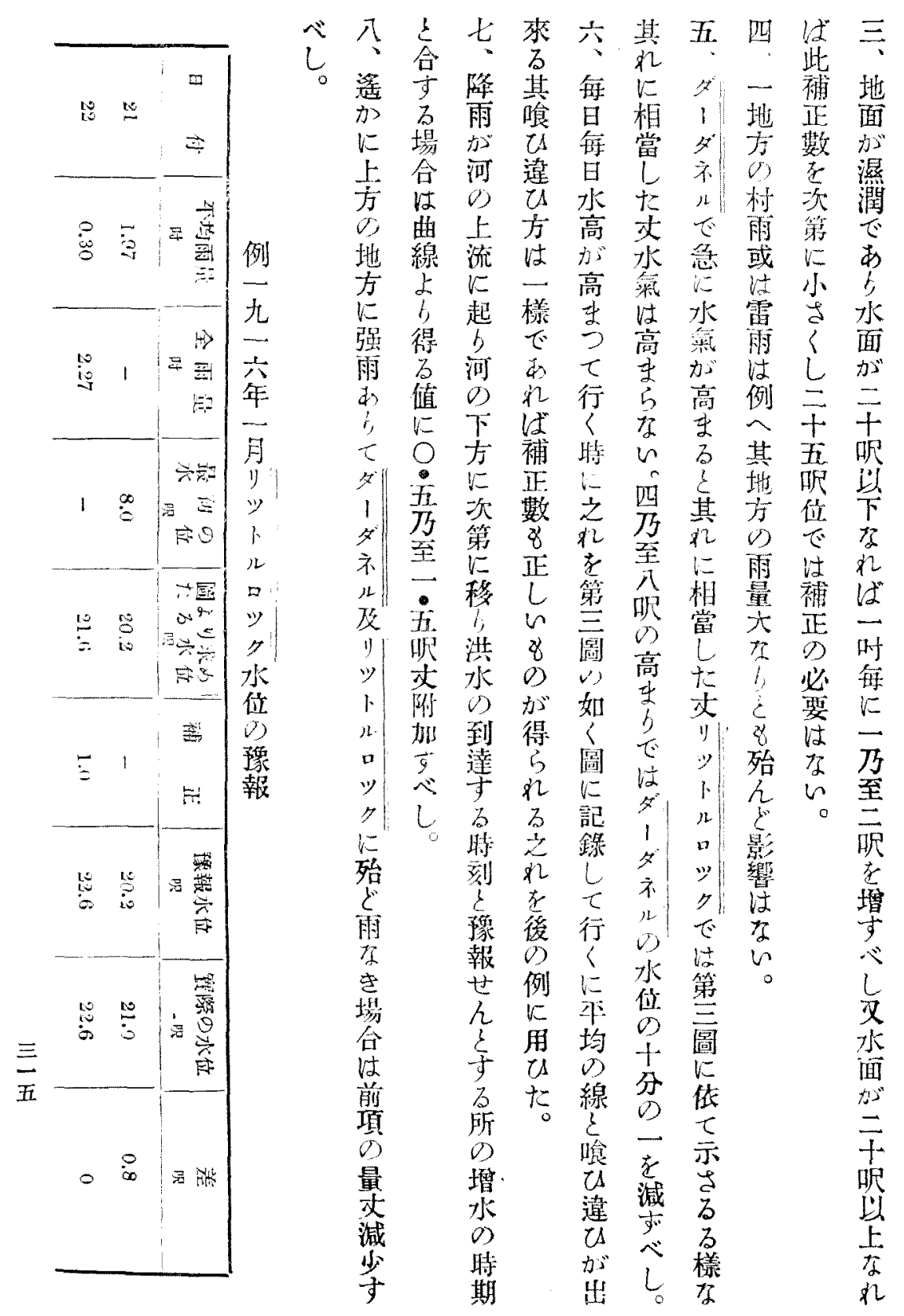


誼荒正所是年 不贲五样月礎吕 敢君位零十花 销 既 荒 寺九立 氭 按卒井に百て敲 君之君建江冨 暲 女碑 設しれ長 顯年せ七た荒 德 故 其る 茾 通踓正名确元 稱相三篦石多告

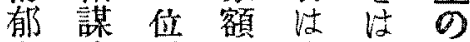
之建䭷注高斯碑 䎲碑一德—學成 荒以等监丈界方 井錦公公一D 氐見爵爵尺普先 考屬德飞一<告 諱跔 川 題呼家乞愿名代 道君達撰七所以

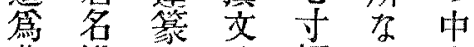
幕满額在幅る央 府天烊五菠 代下踦尽以梨

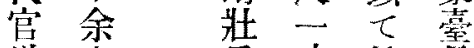
耻委 寸玆長

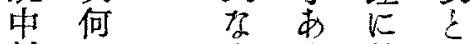
村足台督等 民䡛今本䍃 动重碑年和我

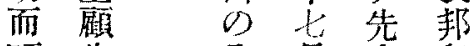
頴先全月生氯 悟公十交篦 好同公残事 學君得日世業 稍任た東号悉 長幕れ京れ緒 入腐底府 昌余左下海開 景帟豐明玉 揭薯治能

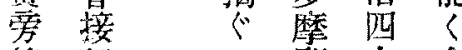
䩦警譬含

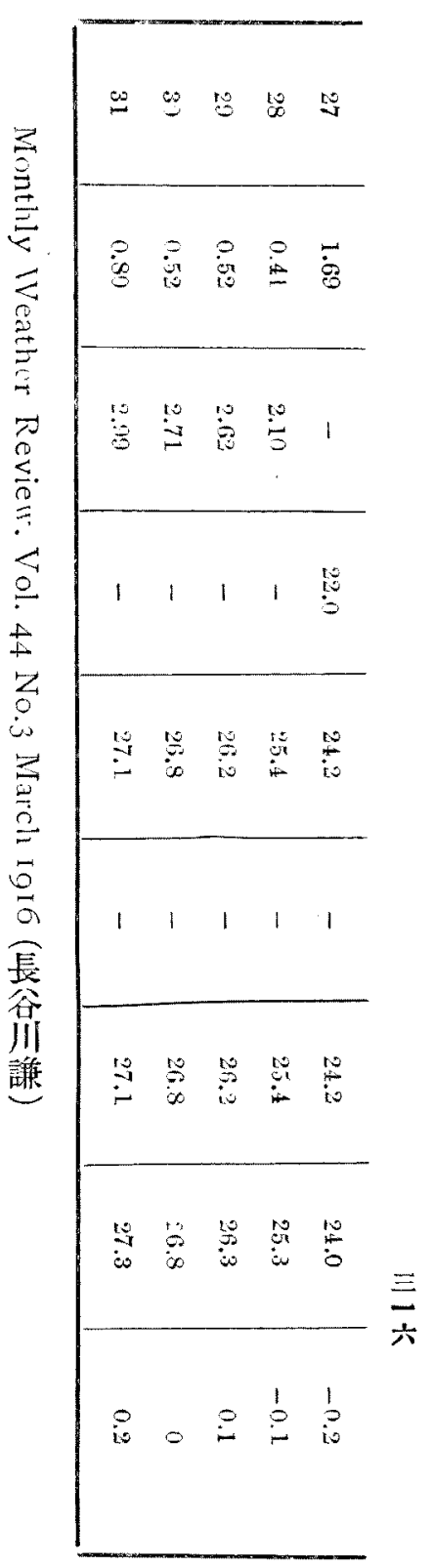

